\title{
The Role of PTEN in Neurodevelopment
}

\author{
Patrick D. Skelton $^{\text {a }}$ Radu V. Stan ${ }^{\mathrm{b}}$ Bryan W. Luikart ${ }^{\mathrm{a}}$ \\ aDepartment of Molecular and Systems Biology, Geisel School of Medicine at Dartmouth, Hanover, NH, USA; \\ ${ }^{b}$ Department of Biochemistry and Cell Biology, Geisel School of Medicine at Dartmouth, Hanover, NH, USA
}

\section{Keywords}

PTEN · Synapse · Autism · Autism spectrum disorder · ASD · Epilepsy

\begin{abstract}
PTEN is a lipid and protein phosphatase that regulates cell growth and survival. Mutations to PTEN are highly penetrant for autism spectrum disorder (ASD). Here, we briefly review the evidence linking PTEN mutations to ASD and the mouse models that have been used to study the role of PTEN in neurodevelopment. We then focus on the cellular phenotypes associated with PTEN loss in neurons, highlighting the role PTEN plays in neuronal proliferation, migration, survival, morphology, and plasticity.

(c) 2020 S. Karger AG, Basel
\end{abstract}

\section{PTEN Mutations and ASD}

Autism spectrum disorder (ASD) is a neurodevelopmental disorder involving impaired social behavior, sensory hypersensitivity, repetitive behavior, and restricted interests. In the USA, 1 in 59 children receive an ASD di- agnosis [1]. ASD is highly heritable, with genetics accounting for about half of ASD risk [2]. Approximately $50 \%$ of cases are expected to arise from the cumulative effects of common alleles each conferring a small degree of risk [3]. Copy number variations or single-gene mutations contribute to an estimated $10 \%$ of total ASD cases [4] and a larger proportion of simplex cases [5]. According to one estimate, as many as $30 \%$ of ASD cases may have a detectable genetic etiology [6]. Although they each account for only a small fraction of cases, single-gene mutations provide a useful starting point for dissecting the developmental etiology of ASD, since biological functions relevant to ASD etiology may be similarly disrupted in both idiopathic and syndromic cases. One gene associated with syndromic ASD risk is the phosphatase and tensin homolog gene (PTEN). The PTEN protein is part of a signaling network that contains multiple ASD-associated gene products and represents a potentially common etiological mechanism for ASD and related neurodevelopmental disorders [7-9]. Here, we briefly review the PTEN protein and the phenotypes associated with PTEN loss of function in humans, before focusing on the structural and functional consequences of PTEN loss in vivo in animal models and what these tell us about PTEN function in neurons.

\section{KARGER}

() 2020 S. Karger AG, Basel

karger@karger.com

www.karger.com/mnp
Bryan W. Luikart

Department of Molecular and Systems Biology, Geisel School of Medicine at Dartmouth 74 College Street, Vail 604

Hanover, NH 03755 (USA)

E-Mail Bryan.W.Luikart@ Dartmouth.edu 


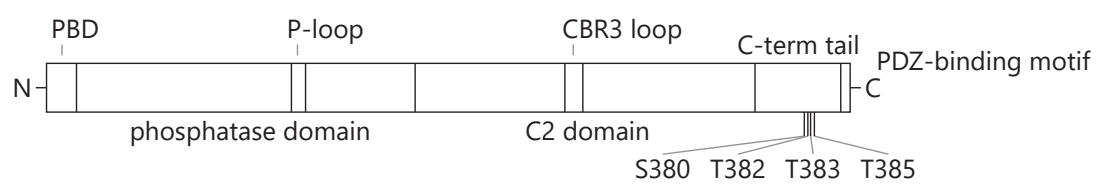

Fig. 1. Major structural features of PTEN. PTEN has an N-terminal PIP2-binding domain (PBD) and phosphatase domain (amino acids 7-185), containing the catalytic P-loop (123-130). A C2 domain (186-351) contains a CBR3 loop from 260-269, which mediates membrane binding. An unstructured C-terminal tail contains multiple phosphorylation sites which inhibit catalytic activity and membrane binding. The terminus of this tail contains a PDZ-binding motif (based on [33] and [58]).

PTEN was originally discovered due to its role as an oncogene $[10,11]$, and was quickly identified as the primary cause of the tumor syndromes Cowden syndrome, Bannayan-Riley-Ruvalcaba syndrome, and LhermitteDuclos disease, collectively referred to as PTEN hamartoma tumor syndromes (PHTS; OMIM \#158350) [1214]. Numerous cases were soon reported of individuals with both PHTS and ASD confirmed to have PTEN mutations $[13,15,16]$, suggesting that PTEN is a risk factor for ASD. PTEN mutations have also been found in individuals with macrocephaly and ASD but lacking a PHTS diagnosis [17-23], indicating incomplete penetrance for both PHTS and ASD. Among individuals with both macrocephaly and ASD, PTEN mutations may be relatively common. The estimated frequency of mutations to protein-coding portions of PTEN in such patients ranges from $<2$ to $20 \%$. Most of the variation is due to the sampling criteria; studies using a more restrictive definition of macrocephaly tend to find a higher mutation rate $[17$, 19-21, 23, 24]. Mutations to other members of the PI3KAKT-mTOR pathway have also been found in cases of comorbid macrocephaly and ASD [25]. Multiple discoveries of de novo PTEN mutations confirm it is a risk gene for ASD [26-30]. Although the penetrance for ASD in humans with PTEN mutations is unknown, a retrospective chart review of patients with known PTEN mutations found macrocephaly in 66\% and ASD diagnoses in 50\%, with high frequencies of dermatological, gastrointestinal, and thyroid problems as well [31].

\section{PTEN Biology}

PTEN is a ubiquitously expressed and evolutionarily conserved dual-specificity protein and lipid phosphatase. In its best-characterized role as a lipid phosphatase, PTEN catalyzes the removal of the 3-phosphate from phosphatidylinositol $(3,4,5)$-phosphate $\left(\mathrm{PIP}_{3}\right)$, generating $\mathrm{PI}(4,5) \mathrm{P}_{2}$ and directly antagonizing the activity of the class I PI3 kinases (PI3K) [32-35]. PIP $_{3}$ recruits and activates a broad variety of effectors by their Pleckstrin homology domains, regulating a broad spectrum of biological functions including growth, survival, gene transcription, protein translation, cytoskeletal organization, and membrane trafficking [32]. The best characterized of these effectors is AKT, which in turn regulates signaling through mTOR and GSK3 $\beta$. Meanwhile, PTEN's protein phosphatase activity targets a number of substrates, including MAPK signaling, which PTEN inhibits [36, 37]. PTEN consists of a phosphatase domain (residues 7-185), a C2 domain, which mediates membrane binding (186351), and a 24-amino acid c-terminus tail (Fig. 1) [38]. An alternate transcript produced from a noncanonical translation initiation site produces small amounts of PTEN-L, which contains an additional 173 amino acids on its Nterminus [39]. PTEN-L is both secreted from the cell [39] and distributed differently within the cell, localizing preferentially away from the nucleus and toward the mitochondria [40].

PTEN is located throughout the cell, where regulation of its location is essential for its function. PTEN's lipid substrate $\mathrm{PIP}_{3}$ is a membrane-bound phospholipid. Therefore, membrane-associated PTEN has the most catalytic activity [41]. PTEN localization to the nucleus contributes to its tumor suppressor activity [42] and its regulation of cell growth [43] while promoting cell survival [44]. Whether PTEN can access PIP3 in the nuclear matrix to regulate mTOR signaling is an open question as there has been evidence both for [43] and against this idea [45]. Monoubiquitination, SUMOylation, and protein-protein interactions increase the rate of PTEN translocation into the nucleus $[42,46,47]$. Impairing the ability of PTEN to localize 
to the nucleus and associate with centromeres leads to an increased frequency of double-strand breaks in DNA [46, 48]. The tumor suppressor properties of nuclear PTEN do not depend on its phosphatase activity, but rather on its ability to associate with the anaphase-promoting complex [49]. However, nuclear PTEN does dephosphorylate PIP $_{3}$ in the nucleus to suppress neuron growth [43]. PTEN-L, the long form of PTEN, is preferentially distributed away from the nucleus [40]. The implications of nuclear PTEN for ASD remain an area of interest.

PTEN activity is dynamically regulated by phosphorylation. The kinase CK2 phosphorylates a cluster of residues on PTEN's C-tail; phosphorylated PTEN is degraded slower by proteasome [50]. In in vitro assays, the membrane affinity of PTEN depends on both the C2 domain and an N-terminal PIP $_{2}$-binding domain [41]. Phosphorylation of the C-tail prevents membrane binding [41]. The phosphorylated residues on the $\mathrm{C}$-tail bind to the $\mathrm{N}$ terminal $\mathrm{PIP}_{2}$-binding domain, competitively blocking the sites of interaction with membrane-bound $\mathrm{PIP}_{2}$ and the $\mathrm{C} 2$ domain [51-53]. The phosphorylation-dependent regulation of the subcellular localization of PTEN is dynamically regulated during cellular growth. For example, in axonal growth cones, most PTEN is phosphorylated and colocalizes with microtubules instead of the membrane [54]. Chemorepellent signals lead to the dephosphorylation of PTEN's C-tail, increasing its affinity for the membrane, where it opposes outgrowth and promotes collapse by dephosphorylating $\mathrm{PIP}_{3}$ [55]. Meanwhile, downstream signaling of growth factor receptors activates CK2 to phosphorylate PTEN, thereby preventing interactions with the membrane [56].

Continued collection of exome and genome sequences from ASD cohorts, PHTS patients, and tumors has led to an expansive library of PTEN mutations associated with pathology. In ASD, tumor syndromes, and tumor tissue, mutations can impact PTEN function in a variety of ways. Mutations to an upstream regulatory element can dampen translation, causing PHTS [57], while point mutations associated with both ASD and cancer lose their function through depressed catalytic activity, instability, and altered subcellular localization [43]. There is a significant overlap between mutations associated with cancer and those associated with ASD [58]. However, it has been proposed that mutations severely affecting catalytic activity have a stronger association with PHTS and cancer, while mutations associated with PHTS and ASD are more likely to produce subtler alterations to stability or subcellular localization. For example, a comparison of the lipid phosphatase activity of several variants found in PHTS and
ASD patients found that while a majority of PHTS-associated variants were completely inactive, most ASD-associated variants retained some lipid phosphatase activity [59]. In another study, a group of PTEN variants found only in ASD were stable and all, at least partially, rescued the morphology of PTEN-knockout neurons, while a group of variants associated with particularly severe PHTS completely lacked the ability to suppress AKT phosphorylation, suggesting a complete loss of function [60]. In a saturation mutagenesis approach in yeast, mutations implicated in PHTS and patient tumors had a greater impact on fitness than mutations implicated only in ASD, and they were more likely to target the catalytic pocket [61]. Collectively, these results suggest that mutations causing a complete loss of function are more likely to result in PHTS, while less severe mutations may contribute to ASD pathology despite retaining some function. However, it is notable that the severity and manifestations of PHTS vary broadly across the patient population, with cognitive function in individuals with PHTS ranging from normal to severely disrupted $[62,63]$. Therefore, the likelihood of developing cancer or ASD in PHTS may depend on factors such as environmental insult of a permissive genetic background, and these factors may be distinct for the two conditions.

PTEN function is important in neurodevelopment. The most common clinical finding in humans with mutated PTEN is macrocephaly [31]. The increased head circumference of patients with PTEN mutations is driven by enlargement of the cerebellum, ventricles, and white matter, although cortex thickness remains normal [64]. Focal abnormalities in white matter are common [65], as are abnormalities of the vasculature [65-67]. It has been proposed that these white matter lesions could contribute to comorbid psychiatric diagnoses such as bipolar disorder, psychosis, obsessive compulsive disorder, general anxiety disorder, and developmental delay [68]. Hemimegalencephaly and focal cortical dysplasias have also been observed in patients with PTEN mutations $[69,70]$, and in patients with mutations elsewhere in the PI3K-AKTmTOR pathway [69]. The cognitive outcomes of patients with PTEN mutations are highly variable. About half have an ASD diagnosis, while about one-third have diagnoses of developmental delay or intellectual disability, and about 1 in 5 have both ASD and a comorbid cognitive disorder [31]. A battery of cognitive function tests administered to patients with Cowden syndrome found that many individuals possessed normal intelligence, while executive and motor functions were the most likely categories to be impaired [63].
Skelton/Stan/Luikart 


\section{Mouse Models of PTEN Loss of Function}

The high penetrance of PTEN mutations for ASD made PTEN a promising candidate to test in animal models. In the mouse, germline PTEN knockout is embryonic lethal [71]. Germline heterozygous and conditional knockout mice display altered neurodevelopment and ASD-associated behaviors, making them a promising model system for studying the biological basis of PTENassociated ASD. Because PTEN mutations in humans are heterozygous, the most genetically similar animal model is mice that are germline heterozygotes. Like humans with PTEN mutations, PTEN heterozygous mice have an enlarged brain. In the mice, this is primarily due to increased proliferation of glia, although enlarged neuronal cell bodies also contribute [72]. These mice exhibit reduced social preference, social interaction time, and aggression, and an increased frequency of repetitive behaviors $[72,73]$. The $m 3 m 4$ mutant strain, which carries 5 germline point mutations in PTEN's C2 domain, affecting subcellular localization, also has an enlarged brain with more glia. In this mouse, males are hypersocial, and both sexes have motor deficits [74]. Neuron-specific conditional PTEN knockout recapitulates many of the features observed in humans with PTEN mutations. In a GFAP-Cre $\times P t e n^{\mathrm{flx} / \mathrm{fl} \mathrm{x}}$ line, in which PTEN is knocked out early in the development of most cerebellar, hippocampal, and cortical neurons, the mice have larger brains with overgrown cerebella and enlarged ventricles, mirroring the characteristics of human Lhermitte-Duclos disease $[75,76]$. In a different GFAP-Cre $\times$ Pten $^{\text {flx/flx }}$ line in which PTEN expression is also lost in glia, axons are hypermyelinated [77]. The NSE-Cre $\times$ Pten $^{\mathrm{flx} / \mathrm{fl} \mathrm{x}}$ mouse loses PTEN expression in a subset of forebrain neurons between birth and 2 weeks of age, leading to an enlarged brain, reduced social preference, impaired sensorimotor gating, learning deficits, and epilepsy $[78,79]$. Therefore, PTEN mutant and neuron-specific conditional knockout mice recapitulate many of the symptoms associated with PTEN mutations in humans, including macrocephaly and behavior alterations that mimic the core symptoms of ASD.

Transgenic mouse lines in which PTEN loss is restricted to specific populations have provided insight to the contributions of specific circuits to altered behavior in PTEN knockout mice. Consistent with the established role of the hippocampus in the etiology of epilepsy, PTEN loss in the dentate gyrus of the hippocampus is sufficient to cause recurrent seizures $[80,81]$. Social behaviors are complex and can be influenced by brain circuits that process reward, fear, motivation, and higher-order cognitive tasks. It is therefore perhaps unsurprising that PTEN deletions in a number of circuits can affect social behavior. In addition to the previously mentioned transgenic lines in which PTEN is lost in multiple brain regions, social behavior is impacted by restricted PTEN loss in midbrain dopaminergic neurons in a DAT-Cre driver line, in cerebellar Purkinje neurons in an L7-Cre driver line, and in cortical interneurons derived from the medial ganglionic eminence (MGE) in an Nkx2.1-Cre driver line [72, 82, 83]. It has been found that inhibiting hyperactive projections from the medial prefrontal cortex to the basolateral amygdala rescues the reduced social preference of PTEN haploinsufficient mice [84]. However, not all circuits implicated in social behavior mediate the altered behaviors associated with PTEN loss, since PTEN knockout in oxytocinergic neurons results in behavior similar to that of wild-type mice except for increased open-field activity [85]. A selection of PTEN conditional knockout lines and the associated behavioral alterations are summarized in Table 1. Together, these studies demonstrate that despite the effects of PTEN loss on the functions of other cell types in the brain, neuronal PTEN loss can drive ASD-associated behavior in a circuit-specific manner.

\section{Proliferation, Differentiation, and Migration}

PTEN is an important regulator of development from the earliest stages, regulating cell proliferation and cell fate. Mice with a homozygous PTEN deletion die before embryonic day 7.5 because of a failure for tissue to appropriately differentiate into endoderm, mesoderm, and ectoderm [71]. Mice lacking only 1 PTEN allele are viable and have increased cell proliferation during brain development. This extra cell proliferation primarily results in the excess production of glial cells as a result of increased signaling through GSK3 $\beta$ [86]. Brain overgrowth is evident starting at birth. The increased number of cortical neurons, first evident at E15.5, normalizes by adulthood, potentially due to increased postnatal apoptosis [86]. In adult mice heterozygous for PTEN, there are increases in the number of astrocytes, microglia, and oligodendrocytes [86]. Increases in progenitor proliferation and cell fate bias toward astrocytes and oligodendrocytes are also observed in a the $m 3 m 4$ homozygous mouse [74]. PTEN deletion can also alter the differentiation of cells at later stages of development; PTEN deletion in GABAergic neurons born in the MGE causes a decrease in the proportion that mature into somatostatin-positive interneu- 
Table 1. Mouse models used to study PTEN loss of function in the context of neurodevelopment, and the behavioral, morphological, and physiological abnormalities observed in each

\begin{tabular}{|c|c|c|c|c|}
\hline Strain & Targeted populations & Behaviors & Morphology and physiology & Reference \\
\hline $\mathrm{Pten}^{-/-}$ & somatic & embryonic lethal & $\begin{array}{l}\text { disrupted differentiation into endo-, meso-, } \\
\text { and ectoderm }\end{array}$ & [71] \\
\hline $\mathrm{Pten}^{+/-}$ & germline heterozygous & $\begin{array}{l}\downarrow \text { social preference } \\
\downarrow \text { social novelty } \\
\downarrow \text { aggression } \\
\uparrow \text { marble burying } \\
\uparrow \text { tail suspension and forced swim } \\
\downarrow \text { dark-light emergence and open field }\end{array}$ & $\begin{array}{l}\text { macrocephaly } \\
\uparrow \text { glia (astrocytes, oligodendrocytes, and microglia) } \\
\text { neuronal hypertrophy } \\
\uparrow \text { axon growth }\end{array}$ & {$[72,73,84,86]$} \\
\hline$m 3 m 4$ & $\begin{array}{l}\text { carries } 5 \text { germline point mutations to the } \\
\text { noncanonical NLS }\end{array}$ & $\begin{array}{l}\uparrow \text { social interaction (males) } \\
\downarrow \text { motor coordination }\end{array}$ & $\begin{array}{l}\text { macrocephaly } \\
\uparrow \text { glia } \\
\uparrow \text { oligodendrocytes } \\
\text { neuronal hypertrophy } \\
\uparrow \text { reactive gliosis }\end{array}$ & [74] \\
\hline $\begin{array}{l}\text { GFAP-Cre } \\
\times \text { Pten }^{\text {flx/flix }}\end{array}$ & $\begin{array}{l}\text { DG, cerebellar granule neurons, some hippocampal } \\
\text { and cortical neurons, by P0-P14 }\end{array}$ & epilepsy & $\begin{array}{l}\text { macrocephaly } \\
\text { cerebellar hyperplasia } \\
\text { neuronal hypertrophy }\end{array}$ & {$[75,76]$} \\
\hline $\begin{array}{l}\text { GFAP-Cre } \\
\times \text { Pten }^{\text {flx/flix }}\end{array}$ & $\begin{array}{l}\text { astrocytes, } 80-90 \% \text { of DG and cerebellar granule } \\
\text { neurons, } 50-80 \% \text { of cortical neurons, by P14 }\end{array}$ & epilepsy & $\begin{array}{l}\text { macrocephaly } \\
\text { cellular hypertrophy } \\
\uparrow \text { astrocyte proliferation } \\
\text { hypermyelination } \\
\uparrow \text { dendritic spines } \\
\uparrow \text { spine size }\end{array}$ & {$[77,117]$} \\
\hline $\begin{array}{l}\text { Emxl-Cre } \\
\times \text { Pten }^{\mathrm{flx} /+} \\
\text { Emx } 1-\text { Cre } \\
\times \text { Pten }^{\mathrm{fls} / \mathrm{fl} x}\end{array}$ & $\begin{array}{l}\text { cortical neurons, astrocytes, and oligodendrocytes, } \\
\text { from corticogenesis }\end{array}$ & $\downarrow$ social preference & $\begin{array}{l}\text { macrocephaly } \\
\text { somatic hypertrophy } \\
\uparrow \text { glia }\end{array}$ & {$[84,86]$} \\
\hline $\begin{array}{l}\text { NSE-Cre } \\
\times \operatorname{Pten}^{\text {flx } \mathrm{flfx}}\end{array}$ & $\begin{array}{l}\text { approximately } 50 \% \text { of excitatory forebrain neurons } \\
\text { by the age of } 4 \text { weeks }\end{array}$ & $\begin{array}{l}\text { epilepsy } \\
\downarrow \text { water maze } \\
\downarrow \text { social novelty } \\
\downarrow \text { social preference } \\
\uparrow \text { startle response } \\
\downarrow \text { time in open field }\end{array}$ & $\begin{array}{l}\text { macrocephaly } \\
\text { neuronal and dendritic hypertrophy } \\
\text { mossy fiber sprouting } \\
\text { ectopic dendrites } \\
\uparrow \text { dendritic spines }\end{array}$ & {$[78,79,92]$} \\
\hline $\begin{array}{l}\text { CamKIIa-Cre } \\
\times \text { Pten }^{\text {flx/flix }}\end{array}$ & excitatory forebrain neurons, at the age of $2-8$ weeks & $\downarrow$ water maze & $\begin{array}{l}\text { normal cell size } \\
\text { laminar-specific dendritic hypertrophy } \\
\text { normal dendritic spines } \\
\downarrow \text { LTP } \\
\downarrow \text { LTD } \\
\downarrow \text { excitability }\end{array}$ & {$[104,106,107]$} \\
\hline $\begin{array}{l}\text { Nkx2.1-Cre } \\
\times \operatorname{Pten}^{\mathrm{fl} / \mathrm{fl}}\end{array}$ & MGE-derived interneurons & $\begin{array}{l}\downarrow \text { social preference } \\
\downarrow \text { novel object interaction }\end{array}$ & $\begin{array}{l}\uparrow \text { PV/SST ratio } \\
\text { cellular hypertrophy } \\
\uparrow \text { IPSCs (on pyramidal neurons) }\end{array}$ & {$[83]$} \\
\hline $\begin{array}{l}\text { DAT-Cre } \\
\times \text { Pten }^{n / f / l x}\end{array}$ & midbrain dopaminergic neurons & $\begin{array}{l}\downarrow \text { social preference } \\
\downarrow \text { social approaches (sex-dependent) }\end{array}$ & $\begin{array}{l}\text { cellular hypertrophy } \\
\uparrow \text { axon growth } \\
\uparrow \text { DA release }\end{array}$ & {$[72,100]$} \\
\hline $\begin{array}{l}\text { L7-Cre } \\
\times \text { Pten }^{\text {flx/flx }}\end{array}$ & Purkinje neurons & $\begin{array}{l}\downarrow \text { social preference } \\
\downarrow \text { social approaches } \\
\downarrow \text { grooming } \\
\text { normal memory }\end{array}$ & $\begin{array}{l}\text { cellular hypertrophy } \\
\uparrow \text { excitatory drive } \\
\downarrow \text { tonic activity }\end{array}$ & {$[82]$} \\
\hline
\end{tabular}

NLS, nuclear localization sequence; MGE, medial ganglionic eminence; PV, parvalbumin; SST, somatostatin; DA, dopamine; IPSCs, inhibitory postsynaptic currents.

rons, and an increase in the proportion that mature to express parvalbumin [83].

The incidence of focal cortical dysplasia in humans with PTEN mutations $[69,70]$ implicates PTEN in neuronal migration. Postnatally generated PTEN-knockout granule neurons in the dentate gyrus migrate further from the subgranular zone, an effect prevented by treatment with the mTORC1 inhibitor rapamycin [87]. Ectopic cerebellar granule neurons have also been observed in conditional PTEN knockout lines [75]. In a model of mTOR hyperactivation driven by in utero electropora- tion with constitutively active Rheb, cortical neurons expressing have impaired migration, failing to reach the outer cortical layers and taking on the identity of deeplayer neurons instead [88]. Normalizing cap-dependent protein translation downstream of mTOR by overexpressing constitutively active $4 \mathrm{E}-\mathrm{BP}$ rescues this cortical mislamination. It is currently unknown whether PTEN loss in the developing cortex results in similar mislamination, or whether currently existing examples of PTENassociated migration defects are similarly dependent on cap-dependent protein translation. 


\section{Morphological Elaboration}

Animal models of PTEN dysfunction demonstrate a role for PTEN in axon growth and guidance. Mice heterozygous for PTEN have an enlarged corpus callosum, and axons arising from cortical neurons are overgrown [84, 86]. The mossy fibers of PTEN knockout dentate gyrus granule neurons are overgrown and frequently have ectopic branches that project back to the dentate gyrus [79, 89]. Loss of tuberous sclerosis complex (TSC) results in a similar phenotype of axon overgrowth and ectopic projections $[90,91]$. Treatment with rapamycin prevents the overgrowth of PTEN-null mossy fiber axons [92], implicating hyperactive mTOR signaling as a driver of axon outgrowth. However, by dynamically modulating $\mathrm{PIP}_{3}$ at the growth cone, PTEN also has a direct mechanistic role in axon growth, branching, and guidance. Axon growth requires accumulation of $\mathrm{PIP}_{3}$ at the leading edge of the growth cone. To maintain this pool of $\mathrm{PIP}_{3}$, PTEN is sequestered away from the membrane [54]. Conversely, the presence of catalytically active PTEN at the growth cone prevents neurite outgrowth. When CK2, an inhibitory PTEN kinase, is prevented from phosphorylating PTEN, the axons of cultured hippocampal neurons fail to grow in response to nerve growth factor [56]. Likewise, the sites at which axonal filopodia sprout are predicted by PI3Kmediated transient increases in $\mathrm{PIP}_{3}$ levels [93], allowing PTEN within the neurite to suppress the formation of new branches by controlling local $\mathrm{PIP}_{3}$ levels. Finally, chemorepellent cues mediate growth cone collapse by recruiting active PTEN to the leading edge of the growth cone $[54,94]$. In cultured chick dorsal root ganglion neurons, chemorepellent Sema3A activation causes PTEN to translocate from microtubules at the center of a neurite to the growth cone membrane, decreasing local $\mathrm{PIP}_{3}$ levels and causing the growth cone to collapse [54]. Similarly, in hippocampal primary cultures, growth cone collapse mediated by Sema4D requires active PTEN. In this process, Sema4D binding to Plexin-B1 to signals through R-Ras GAP to dephosphorylate PTEN, allowing it to enter its active "open" conformation. Additionally, PlexinB1 signaling also suppresses the activity of the inhibitory PTEN kinase CK2 $\alpha$ to prevent PTEN inactivation [55]. Therefore, in addition to driving neurite outgrowth through mTOR activation, PTEN at axonal growth cones plays a direct mechanistic role in regulating outgrowth, branching, and collapse.

The somata and dendrites of PTEN mutant or knockout neurons are enlarged. Neuron-specific conditional knockout mice have enlarged neuronal cell bodies and dendrites in the cerebellum, cortex, and hippocampus, sufficient to cause macrocephaly without abnormally increased numbers of neurons $[75,76,78]$. In various transgenic and virally driven knockout models, neuronal somata are universally enlarged. This includes cerebellar Purkinje neurons [82], granule neurons of the dentate gyrus [95-97], pyramidal neurons in the auditory [98] and motor [99] cortices, and midbrain dopaminergic neurons [100]. Enlarged cell bodies and arbors are also seen in both GABAergic and glutamatergic neurons in vitro [101]. PTEN knockout in dentate gyrus granule neurons increases the number of primary dendrites, dendrites that arise directly from the soma [96], and it decreases the degree of self-avoidance within the dendritic arbor [97], affecting both the sampling of afferent input and the postsynaptic processing of that input.

Somatic overgrowth is gene dose-dependent. Viral shRNA-mediated PTEN knockdown in mature dentate gyrus granule neurons causes somatic hypertrophy [95, 102] to a lesser degree than complete knockout in newborn neurons [103]. In the cortices of PTEN haploinsufficient mice, somatic overgrowth is restricted to neuronal populations with higher endogenous levels of phosphorylated S6, such as layer 5 pyramidal neurons, indicating that populations with higher activity in downstream signaling cascades may be more susceptible to PTEN loss [84]. In later development, the effects of PTEN differ both by cell type and by cellular compartment. Dendritic overgrowth in the cortex of CamKII $-\mathrm{Cre}^{+/-} \times \mathrm{Pten}^{\mathrm{fl} / \mathrm{fll}}$ mice, in which PTEN is lost in forebrain excitatory neurons after several weeks of normal development, is restricted to the apical dendrites of layer $2 / 3$ pyramidal neurons, with no effects on basal dendrites or to layer 5 pyramidal neurons [104].

Neuronal cell bodies in the $m 3 m 4$ mouse, which carries germline mutations reducing the ability of PTEN to associate with the nucleus and the cell membrane, are also hypertrophic [74], indicating that appropriate subcellular localization of PTEN is critical for its regulation of cell growth. Several ASD-associated point mutations in the C2 domain of PTEN decrease the amount of PTEN present in the nucleus; increasing the nuclear localization of 2 of these mutants (D252G and W274L), by adding a canonical nuclear localization sequence (NLS) to the protein, partially rescues the increase in soma size [43]. Overexpression of Y128L-NLS mutant PTEN, which has no protein phosphatase activity but retains some lipid phosphatase activity, partially rescues somatic hypertrophy in PTEN knockout neurons, while G129E-NLS, which is lipid-phosphatase dead but protein-phosphatase capable, 
does not [43]. Thus, the nuclear lipid phosphatase activity by PTEN is important for regulating cell growth.

Mechanistically, both somatic and dendritic overgrowth of PTEN knockout neurons are likely to result from increased cap-dependent protein translation downstream of hyperactive mTORC1. A mechanistic evaluation of dendritic branching in cultured hippocampal neurons revealed that like PTEN knockdown, overexpressed or constitutively active PI3K, AKT, or Ras induce mTORC1-dependent dendritic overgrowth. Meanwhile, dendritic growth is reduced by knockdown of p70S6K or overexpression of 4EBP1 [105]. Somatic and dendritic hypertrophy of PTEN knockout neurons is rescued with rapamycin in vivo $[87,92,104]$. Overexpression of constitutively active Rheb in L2/3 pyramidal neurons results in somatic and dendritic hypertrophy similar to PTEN knockout; both of these phenotypes are rescued by coexpression of constitutively active 4EBP1 [88]. Collectively, these results suggest that PTEN dysfunction drives somatic and dendritic overgrowth by increasing cap-dependent protein translation downstream of mTORC1.

\section{Synaptic Connectivity}

PTEN regulates both the density and strength of glutamatergic synapses. A number of experimental models, including transgenic mice, and a variety of viral gene manipulation schemes have been used to examine the dendritic spine densities of neurons after PTEN loss. Remarkably, the various models show a wide variety of phenotypes, with some showing a robust increase, and others showing no change at all. Among transgenic mouse models, GFAP-Cre $\times$ Pten ${ }^{\mathrm{flx} / \mathrm{fl} \mathrm{x}}$ and NSE-Cre $\times$ Pten $n^{\mathrm{fl} / \mathrm{flx}}$ strains both have increased dendritic spine density in the cortex and hippocampus $[77,78]$. In these models, PTEN is lost in about half the cortical and hippocampal neurons, and in nearly all granule neurons of the cerebellum and dentate gyrus. In the GFAP-driven line, this occurs prenatally, while the NSE-Cre driver line causes PTEN loss within the first 2 weeks after birth. A number of viral strategies to knock out or knock down PTEN have similarly resulted in increased dendritic spine density of dentate gyrus granule neurons, including lentiviral shRNA knockdown [95], retroviral Cre expression in a $P t e n^{\text {flx/flx }}$ mouse [96], and retroviral CRISPR-Cas9-mediated knockout [103]. An AAV Cre-lox system likewise increases dendritic spine density on neurons in the auditory cortex [98]. In all of these models, increased dendritic spine density was associated with increased excit- atory synaptic drive. Both strains of transgenic mice suffer from seizures $[75,79]$, and granule neurons and cortical neurons have both an increased frequency of spontaneous excitatory synaptic events and an increased amplitude of evoked events $[96,98]$. These experiments convincingly demonstrate that, under the right conditions, PTEN loss can dramatically increase excitatory synapse formation on neurons, rendering them hyperexcitable.

Paradoxically, not all models demonstrate the same increase in excitatory synapse formation. CamKIIa-Cre $x$ $P t e n^{\mathrm{fl} / \mathrm{flx}}$ mice do not have increased numbers of dendritic spines in the cortex or in the CA regions of the hippocampus $[104,106]$. Notably, the visual cortical pyramidal neurons in these mice are hypoexcitable with reduced responses to visual stimuli in vivo [107]. Like the GFAPand NSE-Cre driver lines, these mice progressively lose PTEN expression in increasing numbers of cortical neurons with age, leading to mosaic knockout and affecting a majority of principal neurons in the cortex and hippocampus. The primary difference is that in the CamKIIaCre line, Cre expression comes on much later, starting at two weeks and affecting some neurons for the first time as late as 8 weeks of age. Therefore, the CamKIIa-Cre $\times$ $P t e n^{\mathrm{flx} / \mathrm{flx}}$ mice first lose PTEN expression in circuits that are much more mature than in the other model systems. This suggests that with widespread PTEN loss in the brain, the effect on synapses depends on processes that occurred earlier in development.

A number of model systems rely on sparse viral infection to allow visualization using virally driven fluorophore expression. We recently showed that increased dendritic spine density after post-synaptic PTEN knockout in dentate granule neurons depends on the ability of those dendritic spines to find suitable presynaptic contacts, meaning that postsynaptic spine density cannot increase beyond the number of available boutons [108] With sparse virally mediated knockout, we speculate the observed increase in dendritic spine density is primarily due to the ability of the PTEN knockout neurons to outcompete neighboring wild-type neurons for a limited pool of presynaptic terminals. One study that used cellfilling with a patch pipette to visualize knockout neurons in brain slices with dense AAV-mediated PTEN knockout found no change in the dendritic spine density of PTEN knockout neurons. Instead, the only change to the dendritic spines was in their morphology, which was enlarged and more mushroom-like [109]. This study was also performed in adult mice; later onset of PTEN loss could occur after critical periods for arborization have
Skelton/Stan/Luikart 
closed, reducing the genesis or stabilization of new dendritic spines by preventing increases to the number of boutons. Since neurobiological deficits that emerge after developmental critical periods are more likely to be reversible after maturation, a close evaluation of differences between phenotypes in early- and late-onset conditional knockouts may inform which phenotypes might be more amenable to therapeutic interventions later in life.

The increased dendritic spine densities of PTEN knockout neurons are a source of increased synaptic connectivity and excitatory drive. PTEN knockout increases the frequency and the amplitude of excitatory synaptic events [95-98], even when no increase in spine density is observed [109]. Several aspects of the morphology and physiology of PTEN knockout neurons can influence their excitability, including the number of dendritic synapses, synaptic strength, the altered arrangement of branches in the dendritic arbor, and passive membrane properties [96]. The recruitment of presynaptic input appears to be unbiased, with granule neurons and cortical pyramidal neurons recruiting similar amounts of increased input from multiple distinct afferents $[98,108]$. This increased recruitment of excitatory input is not counterbalanced by an increase in the formation of inhibitory synapses [95-97]. The principles by which PTEN governs the excitability of glutamatergic neurons likely apply to other cell types as well. For example, PTEN knockout in MGE-derived interneurons increased the frequency of inhibitory postsynaptic currents on cortical pyramidal neurons [83], suggesting that PTEN loss in GABAergic neurons makes them hyperactive as well. However, the seemingly linear relationship between PTEN function, recruitment of excitatory synaptic input, and hyperexcitability is complicated by the diversity of neurons within the brain. Like other neurons, PTEN knockout in cerebellar Purkinje neurons causes them to recruit increased excitatory input. Contrary to expectations, this increased excitation is insufficient to override other physiological changes (i.e., decreased input resistance) that render the neurons hypoactive. The end result of PTEN knockout in these neurons is a decrease in the tonic firing rate [82]. Therefore, a thorough analysis of ASD-relevant circuits in the PTEN knockout or heterozygous brain may be required to uncover cell-type- and circuit-specific effects of PTEN loss.

The density of dendritic spines is determined by balancing the rates of synapse formation and elimination. Similar to axon growth cones, the formation and motility of dendritic filopodia are driven by $\mathrm{PIP}_{3}$ accumulation at the tip [110], suggesting that PTEN could inhibit inap- propriate spine formation in the wild-type brain by translocating to spine tips to prevent extension or promote collapse, as in axonal filopodia. A large portion of the excess dendritic protrusions on PTEN knockout neurons have a filopodial morphology, suggesting an increase in de novo spine formation [96]. However, in an analysis of the mechanisms of spine density regulation by PTEN, dendritic spine density was regulated by the protein phosphatase function of PTEN but not its lipid phosphatase function, since the expression of the G129E mutant protein, which has protein phosphatase activity but lacks lipid phosphatase activity, was able to rescue dendritic spine density in PTEN-null neurons, while the Y138L point mutant protein, which is selectively protein-phosphatase dead, was not [111]. Results from models of TSC also support an mTOR-independent role for PTEN in the regulation of dendritic spine density, since the loss of TSC proteins does not increase excitatory synaptogenesis [101, $112,113]$. In contrast, hyperactive mTOR could be the driving force behind any deficit in dendritic spine elimination, since dysfunctional autophagy due to mTOR hyperactivation has been implicated in increased spine density due to a lack of autophagy-dependent synapse pruning [114]. A more nuanced analysis is required to determine both the relative contributions of spine formation and spine elimination to the increased connectivity that occurs with PTEN loss, and also which catalytic activities of PTEN are most relevant to each process. This will in turn inform which mechanisms make the most promising therapeutic targets.

Compared to its postsynaptic effects, the effects of PTEN on the presynapse have received less attention. Axonal arbors of PTEN knockout neurons are larger, and in some circuits the frequency of en passant boutons along the axon is increased $[84,89]$, meaning the total number of synapses in the PTEN deficient brain is likely to be increased. The effects of PTEN loss on synaptic function (similar to that on dendritic spine density, may be agedependent. In the hippocampi of GFAP-Cre $\times P t e n^{\text {flx/flx }}$ mice, basal transmission is decreased [77], while in the NSE-Cre $\times P$ ten $^{\mathrm{fl} / \mathrm{flx}}$ mouse it is temporarily increased during a window in early adulthood [115]. In autaptic cultures, PTEN loss causes an increase in the size of the readily releasable pool in both GABAergic and glutamatergic neurons. However, the spontaneous release rate is decreased in this system, while the paired-pulse ratio is increased, indicating a decrease in the efficiency of vesicle fusion [116]. Although treatment with rapamycin rescued the increase in the number of presynaptic vesicles, TSC1 knockout neurons in the same model system do not have 
increased vesicular pool size or altered release rates [101]. Therefore, the changes to the vesicular pool and synaptic release may require the coactivation of $\mathrm{mTOR}$ and one or more other signaling pathways downstream of PTEN.

\section{Conclusion}

PTEN is an upstream regulator of a signaling pathway in which many proteins are implicated in ASD, making it an especially interesting target of study in ASD etiology. The functions of PTEN in brain development are diverse. PTEN and the signal cascades it regulates influence brain development during cell proliferation and differentiation, migration, neurite outgrowth, synaptogenesis, and myelination. It is not an understatement to say that PTEN influences every stage of neurodevelopment, including plasticity in the mature brain. At this point, it is unclear which, or what combination, of this constellation of cellular changes forms the neurobiological basis for the symptoms of ASD. As our understanding of the cellular roles and mechanisms of PTEN improves, so too will our understanding of the etiology of its associated neurodevelopmental disorders, including ASD, epilepsy, and cognitive impairment, potentially leading to the development of new diagnostic and therapeutic tools.

\section{Acknowledgements}

The authors would like to thank the members of the Luikart lab including Michael Williams and Stephanie Getz for critical intellectual input and feedback. We would also like to thank Maxime Guinel and the Dartmouth Electron Microscopy Core for trainings and maintaining the core facility.

\section{Disclosure Statement}

The authors have no conflicts of interest to declare.

\section{Funding Sources}

The work was funded by the National Institutes of Mental Health (R01MH097949; to B.W.L.) and by the National Institute of General Medical Science (R01GM120592; to R.V.S.).

\section{Author Contributions}

P.D.S. wrote the manuscript, R.V.S. edited the manuscript, and B.W.L. conceived and edited the manuscript.

\section{References}

1 Baio J, Wiggins L, Christensen DL, Maenner MJ, Daniels J, Warren Z, et al. Prevalence of Autism Spectrum Disorder Among Children Aged 8 Years - Autism and Developmental Disabilities Monitoring Network, 11 Sites, United States, 2014. MMWR Surveill Summ. 2018 Apr;67(6):1-23.

2 Sandin S, Lichtenstein P, Kuja-Halkola R, Larsson H, Hultman CM, Reichenberg A. The familial risk of autism. JAMA. 2014 May; 311(17):1770-7.

3 Gaugler T, Klei L, Sanders SJ, Bodea CA, Goldberg AP, Lee AB, et al. Most genetic risk for autism resides with common variation. Nat Genet. 2014 Aug;46(8):881-5.

4 Ronemus M, Iossifov I, Levy D, Wigler M. The role of de novo mutations in the genetics of autism spectrum disorders. Nat Rev Genet. $2014 \mathrm{Feb} ; 15(2): 133-41$

5 Sanders SJ, He X, Willsey AJ, Ercan-Sencicek AG, Samocha KE, Cicek AE, et al.; Autism Sequencing Consortium. Insights into Autism Spectrum Disorder Genomic Architecture and Biology from 71 Risk Loci. Neuron. 2015 Sep;87(6):1215-33.

6 Buxbaum JD. Multiple rare variants in the etiology of autism spectrum disorders. Dialogues Clin Neurosci. 2009;11(1):35-43.
7 Winden KD, Ebrahimi-Fakhari D, Sahin M. Abnormal mTOR Activation in Autism. Annu Rev Neurosci. 2018 Jul;41(1):1-23.

8 Santini E, Klann E. Reciprocal signaling between translational control pathways and synaptic proteins in autism spectrum disorders. Sci Signal. 2014 Oct;7(349):re10-10.

9 Magdalon J, Sánchez-Sánchez SM, GriesiOliveira K, Sertié AL. Dysfunctional mTORC1 Signaling: A Convergent Mechanism between Syndromic and Nonsyndromic Forms of $\mathrm{Au}-$ tism Spectrum Disorder? Int J Mol Sci. 2017 Mar;18(3):E659.

10 Steck PA, Pershouse MA, Jasser SA, Yung $\mathrm{WK}$, Lin $\mathrm{H}$, Ligon $\mathrm{AH}$, et al. Identification of a candidate tumour suppressor gene, MMAC1, at chromosome 10q23.3 that is mutated in multiple advanced cancers. Nat Genet. 1997 Apr;15(4):356-62.

11 Liaw D, Marsh DJ, Li J, Dahia PL, Wang SI, Zheng Z, et al. Germline mutations of the PTEN gene in Cowden disease, an inherited breast and thyroid cancer syndrome. Nat Genet. 1997 May;16(1):64-7.

12 Marsh DJ, Dahia PL, Zheng Z, Liaw D, Parsons R, Gorlin RJ, et al. Germline mutations in PTEN are present in Bannayan-Zonana syndrome. Nat Genet. 1997 Aug;16(4):333-4.
13 Zori RT, Marsh DJ, Graham GE, Marliss EB, Eng C. Germline PTEN mutation in a family with Cowden syndrome and Bannayan-RileyRuvalcaba syndrome. Am J Med Genet. 1998 Dec;80(4):399-402.

14 Nelen MR, van Staveren WC, Peeters EA, Hassel MB, Gorlin RJ, Hamm H, et al. Germline mutations in the PTEN/MMAC1 gene in patients with Cowden disease. Hum Mol Genet. 1997 Aug;6(8):1383-7.

15 Boccone L, Dessì V, Zappu A, Piga S, Piludu MB, Rais M, et al. Bannayan-Riley-Ruvalcaba syndrome with reactive nodular lymphoid hyperplasia and autism and a PTEN mutation. Am J Med Genet A. 2006 Sep;140(18): 1965-9.

16 Goffin A, Hoefsloot LH, Bosgoed E, Swillen A, Fryns JP. PTEN mutation in a family with Cowden syndrome and autism. Am J Med Genet. 2001 Aug; 105(6):521-4.

17 Butler MG, Dasouki MJ, Zhou XP, Talebizadeh Z, Brown M, Takahashi TN, et al. Subset of individuals with autism spectrum disorders and extreme macrocephaly associated with germline PTEN tumour suppressor gene mutations. J Med Genet. 2005 Apr; 42(4):318-21. 
18 Herman GE, Butter E, Enrile B, Pastore M, Prior TW, Sommer A. Increasing knowledge of PTEN germline mutations: two additional patients with autism and macrocephaly. Am J Med Genet A. 2007 Mar; 143A(6):589-93.

19 McBride KL, Varga EA, Pastore MT, Prior TW, Manickam K, Atkin JF, et al. Confirmation study of PTEN mutations among individuals with autism or developmental delays/ mental retardation and macrocephaly. Autism Res. 2010 Jun;3(3):137-41.

20 Varga EA, Pastore M, Prior T, Herman GE, McBride KL. The prevalence of PTEN mutations in a clinical pediatric cohort with autism spectrum disorders, developmental delay, and macrocephaly. Genet Med. 2009 Feb; 11(2):111-7.

21 Orrico A, Galli L, Buoni S, Orsi A, Vonella G, Sorrentino V. Novel PTEN mutations in neurodevelopmental disorders and macrocephaly. Clin Genet. 2009 Feb;75(2):195-8.

22 Hobert JA, Embacher R, Mester JL, Frazier TW 2nd, Eng C. Biochemical screening and PTEN mutation analysis in individuals with autism spectrum disorders and macrocephaly. Eur J Hum Genet. 2014 Feb;22(2):2736.

23 Busa T, Milh M, Degardin N, Girard N, Sigaudy S, Longy M, et al. Clinical presentation of PTEN mutations in childhood in the absence of family history of Cowden syndrome. Eur J Paediatr Neurol. 2015 Mar; 19(2):188-92.

24 Buxbaum JD, Cai G, Chaste P, Nygren G, Goldsmith J, Reichert J, et al. Mutation screening of the PTEN gene in patients with autism spectrum disorders and macrocephaly. Am J Med Genet B Neuropsychiatr Genet. 2007 Jun;144B(4):484-91.

25 Yeung KS, Tso WW, Ip JJ, Mak CC, Leung $\mathrm{GK}$, Tsang $\mathrm{MH}$, et al. Identification of mutations in the PI3K-AKT-mTOR signalling pathway in patients with macrocephaly and developmental delay and/or autism. Mol Autism. 2017 Dec;8(1):66.

26 O’Roak BJ, Vives L, Fu W, Egertson JD, Stanaway IB, Phelps IG, et al. Multiplex targeted sequencing identifies recurrently mutated genes in autism spectrum disorders. Science. 2012 Dec;338(6114):1619-22.

27 O’Roak BJ, Vives L, Girirajan S, Karakoc E, Krumm N, Coe BP, et al. Sporadic autism exomes reveal a highly interconnected protein network of de novo mutations. Nature. 2012 Apr;485(7397):246-50.

28 Codina-Solà $M$, Rodríguez-Santiago $B$, Homs A, Santoyo J, Rigau M, Aznar-Laín G, et al. Integrated analysis of whole-exome sequencing and transcriptome profiling in males with autism spectrum disorders. Mol Autism. 2015 Apr;6(1):21.

29 De Rubeis S, He X, Goldberg AP, Poultney CS, Samocha K, Cicek AE, et al.; UK10K Consortium. Synaptic, transcriptional and chromatin genes disrupted in autism. Nature. 2014 Nov;515(7526):209-15.
30 Satterstrom FK, et al. [Internet] Large-scale exome sequencing study implicates both developmental and functional changes in the neurobiology of autism [cited 2018 Nov 30]. Available from: https://doi.org/10.1101/484113.

31 Hansen-Kiss E, Beinkampen S, Adler B, Frazier T, Prior T, Erdman S, et al. A retrospective chart review of the features of PTEN hamartoma tumour syndrome in children. J Med Genet. 2017 Jul;54(7):471-8.

32 Hawkins PT, Anderson KE, Davidson K, Stephens LR. Signalling through Class I PI3Ks in mammalian cells. Biochem Soc Trans. 2006 Nov;34(Pt 5):647-62.

33 Shi Y, Paluch BE, Wang X, Jiang X. PTEN at a glance. J Cell Sci. 2012 Oct;125(Pt 20):4687-92.

34 Myers MP, Pass I, Batty IH, Van der Kaay J, Stolarov JP, Hemmings BA, et al. The lipid phosphatase activity of PTEN is critical for its tumor supressor function. Proc Natl Acad Sci USA. 1998 Nov;95(23):13513-8.

35 Stambolic V, Suzuki A, de la Pompa JL, Brothers GM, Mirtsos C, Sasaki T, et al. Negative regulation of $\mathrm{PKB} / \mathrm{Akt}$-dependent cell survival by the tumor suppressor PTEN. Cell. 1998 Oct;95(1):29-39.

36 Myers MP, Stolarov JP, Eng C, Li J, Wang SI, Wigler MH, et al. P-TEN, the tumor suppressor from human chromosome 10q23, is a dual-specificity phosphatase. Proc Natl Acad Sci USA. 1997 Aug;94(17):9052-7.

37 Gu J, Tamura M, Yamada KM. Tumor suppressor PTEN inhibits integrin- and growth factor-mediated mitogen-activated protein (MAP) kinase signaling pathways. J Cell Biol. 1998 Nov;143(5):1375-83.

38 Lee JO, Yang H, Georgescu MM, Di Cristofano A, Maehama T, Shi Y, et al. Crystal structure of the PTEN tumor suppressor: implications for its phosphoinositide phosphatase activity and membrane association. Cell. 1999 Oct;99(3):323-34.

39 Hopkins BD, Fine B, Steinbach N, Dendy M, Rapp Z, Shaw J, et al. A secreted PTEN phosphatase that enters cells to alter signaling and survival. Science. 2013 Jul;341(6144):399-402.

40 Liang H, He S, Yang J, Jia X, Wang P, Chen X, et al. PTENa, a PTEN isoform translated through alternative initiation, regulates mitochondrial function and energy metabolism. Cell Metab. 2014 May;19(5):836-48.

41 Das S, Dixon JE, Cho W. Membrane-binding and activation mechanism of PTEN. Proc Natl Acad Sci USA. 2003 Jun;100(13):7491-6.

42 Trotman LC, Wang X, Alimonti A, Chen Z, Teruya-Feldstein J, Yang H, et al. Ubiquitination regulates PTEN nuclear import and tumor suppression. Cell. 2007 Jan;128(1):141-56.

43 Fricano-Kugler CJ, et al. Nuclear Excluded Autism-Associated Phosphatase and Tensin Homolog Mutations Dysregulate Neuronal Growth. Biol Psychiatry. 2018;84(4):265-77.

44 Howitt J, Lackovic J, Low LH, Naguib A, Macintyre A, Goh CP, et al. Ndfip1 regulates nuclear Pten import in vivo to promote neuronal survival following cerebral ischemia. J Cell Biol. 2012 Jan;196(1):29-36.
45 Lindsay Y, McCoull D, Davidson L, Leslie NR, Fairservice A, Gray A, et al. Localization of agonist-sensitive PtdIns(3,4,5)P3 reveals a nuclear pool that is insensitive to PTEN expression. J Cell Sci. 2006 Dec;119(Pt 24): 5160-8.

46 Bassi C, Ho J, Srikumar T, Dowling RJ, Gorrini C, Miller SJ, et al. Nuclear PTEN controls DNA repair and sensitivity to genotoxic stress. Science. 2013 Jul;341(6144): 395-9.

47 Nguyen HN, Afkari Y, Senoo H, Sesaki H, Devreotes PN, Iijima M. Mechanism of human PTEN localization revealed by heterologous expression in Dictyostelium. Oncogene. 2014 Dec;33(50):5688-96.

48 Shen WH, Balajee AS, Wang J, Wu H, Eng C, Pandolfi PP, et al. Essential role for nuclear PTEN in maintaining chromosomal integrity. Cell. 2007 Jan;128(1):157-70.

49 Song MS, Carracedo A, Salmena L, Song SJ, Egia A, Malumbres M, et al. Nuclear PTEN regulates the APC-CDH1 tumor-suppressive complex in a phosphatase-independent manner. Cell. 2011 Jan;144(2):187-99.

50 Torres J, Pulido R. The tumor suppressor PTEN is phosphorylated by the protein kinase CK2 at its $\mathrm{C}$ terminus. Implications for PTEN stability to proteasome-mediated degradation. J Biol Chem. 2001 Jan;276(2):9938.

51 Bolduc D, Rahdar M, Tu-Sekine B, Sivakumaren SC, Raben D, Amzel LM, et al. Phosphorylation-mediated PTEN conformational closure and deactivation revealed with protein semisynthesis. eLife. $2013 \mathrm{Jul}$; 2:e00691.

52 Rahdar M, Inoue $\mathrm{T}$, Meyer $\mathrm{T}$, Zhang J, Vazquez F, Devreotes PN. A phosphorylation-dependent intramolecular interaction regulates the membrane association and activity of the tumor suppressor PTEN. Proc Natl Acad Sci USA. 2009 Jan;106(2): $480-5$.

53 Chen Z, Dempsey DR, Thomas SN, Hayward D, Bolduc DM, Cole PA. Molecular Features of Phosphatase and Tensin Homolog (PTEN) Regulation by C-terminal Phosphorylation. J Biol Chem. 2016 Jul;291(27):14160-9.

54 Chadborn NH, Ahmed AI, Holt MR, Prinjha R, Dunn GA, Jones GE, et al. PTEN couples Sema3A signalling to growth cone collapse. J Cell Sci. 2006 Mar;119(Pt 5):951-7.

55 Oinuma I, Ito Y, Katoh H, Negishi M. Semaphorin 4D/Plexin-B1 stimulates PTEN activity through R-Ras GTPase-activating protein activity, inducing growth cone collapse in hippocampal neurons. J Biol Chem. 2010 Sep; 285(36):28200-9.

56 Arevalo MA, Rodríguez-Tébar A. Activation of casein kinase II and inhibition of phosphatase and tensin homologue deleted on chromosome 10 phosphatase by nerve growth factor/p75NTR inhibit glycogen synthase kinase-3beta and stimulate axonal growth. Mol Biol Cell. 2006 Aug;17(8): 3369-77. 
57 Zhou XP, Waite KA, Pilarski R, Hampel $\mathrm{H}$, Fernandez MJ, Bos C, et al. Germline PTEN promoter mutations and deletions in Cowden/Bannayan-Riley-Ruvalcaba syndrome result in aberrant PTEN protein and dysregulation of the phosphoinositol-3-kinase/Akt pathway. Am J Hum Genet. 2003 Aug;73(2):404-11.

58 Kreis P, Leondaritis G, Lieberam I, Eickholt BJ. Subcellular targeting and dynamic regulation of PTEN: implications for neuronal cells and neurological disorders. Front $\mathrm{Mol} \mathrm{Neu-}$ rosci. 2014 Apr;7(23):23.

59 Rodríguez-Escudero I, Oliver MD, AndrésPons A, Molina M, Cid VJ, Pulido R. A comprehensive functional analysis of PTEN mutations: implications in tumor- and autismrelated syndromes. Hum Mol Genet. 2011 Nov;20(21):4132-42.

60 Spinelli L, Black FM, Berg JN, Eickholt BJ, Leslie NR. Functionally distinct groups of inherited PTEN mutations in autism and tumour syndromes. J Med Genet. 2015 Feb; 52(2):128-34

61 Mighell TL, Evans-Dutson S, O’Roak BJ. A Saturation Mutagenesis Approach to Understanding PTEN Lipid Phosphatase Activity and Genotype-Phenotype Relationships. Am J Hum Genet. 2018 May;102(5):943-55.

62 Lachlan KL, Lucassen AM, Bunyan D, Temple IK. Cowden syndrome and Bannayan Riley Ruvalcaba syndrome represent one condition with variable expression and age-related penetrance: results of a clinical study of PTEN mutation carriers. J Med Genet. 2007 Sep; 44(9):579-85.

63 Busch RM, Chapin JS, Mester J, Ferguson L, Haut JS, Frazier TW, et al. Cognitive characteristics of PTEN hamartoma tumor syndromes. Genet Med. 2013 Jul;15(7):548-53.

64 Frazier TW, Embacher R, Tilot AK, Koenig K, Mester J, Eng C. Molecular and phenotypic abnormalities in individuals with germline heterozygous PTEN mutations and autism. Mol Psychiatry. 2015 Sep;20(9):1132-8.

65 Vanderver A, Tonduti D, Kahn I, Schmidt J, Medne L, Vento J, et al. Characteristic brain magnetic resonance imaging pattern in patients with macrocephaly and PTEN mutations. Am J Med Genet A. 2014 Mar;164A(3): 627-33.

66 Lok C, Viseux V, Avril MF, Richard MA, Gondry-Jouet C, Deramond H, et al.; Cancerology Group of the French Society of Dermatology. Brain magnetic resonance imaging in patients with Cowden syndrome. Medicine (Baltimore). 2005 Mar;84(2):129-36.

67 Tan WH, Baris HN, Burrows PE, Robson CD, Alomari AI, Mulliken JB, et al. The spectrum of vascular anomalies in patients with PTEN mutations: implications for diagnosis and management. J Med Genet. 2007 Sep;44(9): 594-602.

68 Balci TB, Davila J, Lewis D, Boafo A, Sell E, Richer J, et al. Broad spectrum of neuropsychiatric phenotypes associated with white matter disease in PTEN hamartoma tumor syndrome. Am J Med Genet B Neuropsychiatr Genet. 2018 Jan;177(1):101-9.

69 Jansen LA, Mirzaa GM, Ishak GE, O’Roak BJ, Hiatt JB, Roden WH, et al. PI3K/AKT pathway mutations cause a spectrum of brain malformations from megalencephaly to focal cortical dysplasia. Brain. 2015 Jun;138(Pt 6): 1613-28.

70 Child ND, Cascino GD. Mystery case: cowden syndrome presenting with partial epilepsy related to focal cortical dysplasia. Neurology. 2013 Sep;81(13):e98-9.

71 Di Cristofano A, Pesce B, Cordon-Cardo C, Pandolfi PP. Pten is essential for embryonic development and tumour suppression. Nat Genet. 1998 Aug;19(4):348-55.

72 Clipperton-Allen AE, Page DT. Pten haploinsufficient mice show broad brain overgrowth but selective impairments in autism-relevant behavioral tests. Hum Mol Genet. 2014 Jul; 23(13):3490-505.

73 Clipperton-Allen AE, Page DT. Decreased aggression and increased repetitive behavior in Pten haploinsufficient mice. Genes Brain Behav. 2015 Feb;14(2):145-57.

74 Tilot AK, Gaugler MK, Yu Q, Romigh T, Yu W, Miller RH, et al. Germline disruption of Pten localization causes enhanced sex-dependent social motivation and increased glial production. Hum Mol Genet. 2014 Jun; 23(12):3212-27.

75 Backman SA, Stambolic V, Suzuki A, Haight J, Elia A, Pretorius J, et al. Deletion of Pten in mouse brain causes seizures, ataxia and defects in soma size resembling Lhermitte- $\mathrm{Du}$ clos disease. Nat Genet. 2001 Dec;29(4):396403.

76 Kwon CH, Zhu X, Zhang J, Knoop LL, Tharp $\mathrm{R}$, Smeyne RJ, et al. Pten regulates neuronal soma size: a mouse model of Lhermitte-Duclos disease. Nat Genet. 2001 Dec;29(4):40411.

77 Fraser MM, Bayazitov IT, Zakharenko SS, Baker SJ. Phosphatase and tensin homolog, deleted on chromosome 10 deficiency in brain causes defects in synaptic structure, transmission and plasticity, and myelination abnormalities. Neuroscience. 2008 Jan; 151(2):476-88

78 Kwon CH, Luikart BW, Powell CM, Zhou J, Matheny SA, Zhang W, et al. Pten regulates neuronal arborization and social interaction in mice. Neuron. 2006 May;50(3):377-88.

79 Ogawa S, Kwon CH, Zhou J, Koovakkattu D, Parada LF, Sinton CM. A seizure-prone phenotype is associated with altered free-running rhythm in Pten mutant mice. Brain Res. 2007 Sep;1168:112-23.

80 Pun RY, Rolle IJ, Lasarge CL, Hosford BE, Rosen JM, Uhl JD, et al. Excessive activation of mTOR in postnatally generated granule cells is sufficient to cause epilepsy. Neuron. 2012 Sep;75(6):1022-34.

81 Amiri A, Cho W, Zhou J, Birnbaum SG, Sinton CM, McKay RM, et al. Pten deletion in adult hippocampal neural stem/progenitor cells causes cellular abnormalities and alters neurogenesis. J Neurosci. 2012 Apr;32(17): 5880-90.

82 Cupolillo D, Hoxha E, Faralli A, De Luca A, Rossi F, Tempia F, et al. Autistic-Like Traits and Cerebellar Dysfunction in Purkinje Cell PTEN Knock-Out Mice. Neuropsychopharmacology. 2016 May;41(6):1457-66.

83 Vogt D, Cho KK, Lee AT, Sohal VS, Rubenstein JL. The parvalbumin/somatostatin ratio is increased in Pten mutant mice and by human PTEN ASD alleles. Cell Rep. 2015 May; 11(6):944-56.

84 Huang WC, Chen Y, Page DT. Hyperconnectivity of prefrontal cortex to amygdala projections in a mouse model of macrocephaly/autism syndrome. Nat Commun. 2016 Nov; 7(1):13421.

85 Clipperton-Allen AE, Chen Y, Page DT. Autism-relevant behaviors are minimally impacted by conditional deletion of Pten in oxytocinergic neurons. Autism Res. 2016 Dec; 9(12):1248-62.

86 Chen Y, Huang WC, Séjourné J, ClippertonAllen AE, Page DT. Pten Mutations Alter Brain Growth Trajectory and Allocation of Cell Types through Elevated $\beta$-Catenin Signaling. J Neurosci. 2015 Jul;35(28):10252-67.

87 Getz SA, DeSpenza T Jr, Li M, Luikart BW. Rapamycin prevents, but does not reverse, aberrant migration in Pten knockout neurons. Neurobiol Dis. 2016 Sep;93:12-20.

88 Lin TV, Hsieh L, Kimura T, Malone TJ, Bordey A. Normalizing translation through $4 \mathrm{E}$ BP prevents mTOR-driven cortical mislamination and ameliorates aberrant neuron integration. Proc Natl Acad Sci USA. 2016 Oct; 113(40):11330-5

89 LaSarge CL, Santos VR, Danzer SC. PTEN deletion from adult-generated dentate granule cells disrupts granule cell mossy fiber axon structure. Neurobiol Dis. 2015 Mar;75:14250.

90 Nie D, Di Nardo A, Han JM, Baharanyi H, Kramvis I, Huynh T, et al. Tsc2-Rheb signaling regulates EphA-mediated axon guidance. Nat Neurosci. 2010 Feb;13(2):163-72.

91 Choi YJ, Di Nardo A, Kramvis I, Meikle L, Kwiatkowski DJ, Sahin M, et al. Tuberous sclerosis complex proteins control axon formation. Genes Dev. 2008 Sep;22(18):248595.

92 Zhou J, Blundell J, Ogawa S, Kwon CH, Zhang $\mathrm{W}$, Sinton C, et al. Pharmacological inhibition of mTORC1 suppresses anatomical, cellular, and behavioral abnormalities in neural-specific Pten knock-out mice. J Neurosci. 2009 Feb;29(6):1773-83.

93 Ketschek A, Gallo G. Nerve growth factor induces axonal filopodia through localized microdomains of phosphoinositide 3-kinase activity that drive the formation of cytoskeletal precursors to filopodia. J Neurosci. 2010 Sep; 30(36): 12185-97.

94 Henle SJ, Carlstrom LP, Cheever TR, Henley JR. Differential role of PTEN phosphatase in chemotactic growth cone guidance. J Biol Chem. 2013 Jul;288(29):20837-42. 
95 Luikart BW, Schnell E, Washburn EK, Bensen AL, Tovar KR, Westbrook GL. Pten knockdown in vivo increases excitatory drive onto dentate granule cells. J Neurosci. 2011 Mar;31(11):4345-54.

96 Williams MR, DeSpenza T Jr, Li M, Gulledge AT, Luikart BW. Hyperactivity of newborn Pten knock-out neurons results from increased excitatory synaptic drive. J Neurosci. 2015 Jan;35(3):943-59.

97 Santos VR, Pun RY, Arafa SR, LaSarge CL, Rowley S, Khademi S, et al. PTEN deletion increases hippocampal granule cell excitability in male and female mice. Neurobiol Dis. 2017 Dec;108:339-51.

98 Xiong Q, Oviedo HV, Trotman LC, Zador AM. PTEN regulation of local and longrange connections in mouse auditory cortex. J Neurosci. 2012 Feb;32(5):1643-52.

99 Gallent EA, Steward O. Neuronal PTEN deletion in adult cortical neurons triggers progressive growth of cell bodies, dendrites, and axons. Exp Neurol. 2018 May;303:12-28.

100 Diaz-Ruiz O, Zapata A, Shan L, Zhang Y, Tomac AC, Malik N, et al. Selective deletion of PTEN in dopamine neurons leads to trophic effects and adaptation of striatal medium spiny projecting neurons. PLoS One. 2009 Sep;4(9):e7027.

101 Weston MC, Chen H, Swann JW. Loss of mTOR repressors Tscl or Pten has divergent effects on excitatory and inhibitory synaptic transmission in single hippocampal neuron cultures. Front Mol Neurosci. 2014 Feb;7(1):1.

102 Fricano CJ, Despenza T Jr, Frazel PW, Li M, O’Malley AJ, Westbrook GL, et al. Fatty acids increase neuronal hypertrophy of Pten knockdown neurons. Front Mol Neurosci. 2014 Apr;7:30.
103 Williams MR, Fricano-Kugler CJ, Getz SA, Skelton PD, Lee J, Rizzuto CP, et al. A Retroviral CRISPR-Cas9 System for Cellular Autism-Associated Phenotype Discovery in Developing Neurons. Sci Rep. 2016 May; 6(1):25611.

104 Chow DK, Groszer M, Pribadi M, Machniki M, Carmichael ST, Liu X, et al. Laminar and compartmental regulation of dendritic growth in mature cortex. Nat Neurosci. 2009 Feb;12(2):116-8.

105 Jaworski J, Spangler S, Seeburg DP, Hoogenraad CC, Sheng M. Control of dendritic arborization by the phosphoinositide- $3^{\prime}$ kinase-Akt-mammalian target of rapamycin pathway. J Neurosci. 2005 Dec;25(49): 11300-12.

106 Sperow M, Berry RB, Bayazitov IT, Zhu G, Baker SJ, Zakharenko SS. Phosphatase and tensin homologue (PTEN) regulates synaptic plasticity independently of its effect on neuronal morphology and migration. J Physiol. 2012 Feb;590(4):777-92.

107 Garcia-Junco-Clemente P, Chow DK, Tring E, Lazaro MT, Trachtenberg JT, Golshani P. Overexpression of calcium-activated potassium channels underlies cortical dysfunction in a model of PTEN-associated autism. Proc Natl Acad Sci USA. 2013 Nov; 110(45): 18297-302.

108 Skelton PD, Frazel PW, Lee D, Suh H, Luikart BW. Pten loss results in inappropriate excitatory connectivity. Mol Psychiatry. 2019 Nov;24(11):1627-40.

109 Haws ME, Jaramillo TC, Espinosa F, Widman AJ, Stuber GD, Sparta DR, et al. PTEN knockdown alters dendritic spine/protrusion morphology, not density. J Comp Neurol. 2014 Apr;522(5):1171-90.
110 Luikart BW, Zhang W, Wayman GA, Kwon $\mathrm{CH}$, Westbrook GL, Parada LF. Neurotrophin-dependent dendritic filopodial motility: a convergence on PI3K signaling. J Neurosci. 2008 Jul;28(27):7006-12.

111 Zhang XC, Piccini A, Myers MP, Van Aelst L, Tonks NK. Functional analysis of the protein phosphatase activity of PTEN. Biochem J. 2012 Jun;444(3):457-64.

112 Bateup HS, Takasaki KT, Saulnier JL, Denefrio CL, Sabatini BL. Loss of Tsc1 in vivo impairs hippocampal mGluR-LTD and increases excitatory synaptic function. J Neurosci. 2011 Jun;31(24):8862-9.

113 Meikle L, Pollizzi K, Egnor A, Kramvis I, Lane H, Sahin M, et al. Response of a neuronal model of tuberous sclerosis to mammalian target of rapamycin (mTOR) inhibitors: effects on mTORC1 and Akt signaling lead to improved survival and function. J Neurosci. 2008 May;28(21):5422-32.

114 Tang G, Gudsnuk K, Kuo SH, Cotrina ML Rosoklija G, Sosunov A, et al. Loss of mTORdependent macroautophagy causes autisticlike synaptic pruning deficits. Neuron. 2014 Sep;83(5):1131-43.

115 Takeuchi K, Gertner MJ, Zhou J, Parada LF, Bennett MV, Zukin RS. Dysregulation of synaptic plasticity precedes appearance of morphological defects in a Pten conditional knockout mouse model of autism. Proc Natl Acad Sci USA. 2013 Mar;110(12):4738-43.

116 Weston MC, Chen H, Swann JW. Multiple roles for mammalian target of rapamycin signaling in both glutamatergic and GABAergic synaptic transmission. Neurosci. 2012 Aug;32(33):11441-52.

117 Fraser MM, Zhu X, Kwon CH, Uhlmann EJ, Gutmann DH, Baker SJ. Pten loss causes hypertrophy and increased proliferation of astrocytes in vivo. Cancer Res. 2004 Nov; 64(21):7773-9. 